Wilfrid Laurier University

Scholars Commons @ Laurier

Psychology Faculty Publications

Psychology

Spring 2003

\title{
A Process and Outcome Evaluation of a Shelter for Homeless Young Women
}

Theresa Dostaler

Wilfrid Laurier University

Geoffrey Nelson

Wilfrid Laurier University, gnelson@wlu.ca

Follow this and additional works at: https://scholars.wlu.ca/psyc_faculty

Part of the Psychiatry and Psychology Commons

\section{Recommended Citation}

Dostaler, Theresa and Nelson, Geoffrey, "A Process and Outcome Evaluation of a Shelter for Homeless Young Women" (2003). Psychology Faculty Publications. 19.

https://scholars.wlu.ca/psyc_faculty/19

This Article is brought to you for free and open access by the Psychology at Scholars Commons @ Laurier. It has been accepted for inclusion in Psychology Faculty Publications by an authorized administrator of Scholars Commons@Laurier. For more information, please contact scholarscommons@wlu.ca. 


\title{
A PROCESS AND OUTCOME EVALUATION OF A SHELTER FOR HOMELESS YOUNG WOMEN
}

\author{
THERESA DOSTALER \\ Ottawa, Ontario \\ and \\ GEOFFREY NELSON \\ Wilfrid Laurier University
}

\begin{abstract}
To evaluate the processes and outcomes of a short-term shelter, both quantitative and qualitative data were gathered via participant observation, focus group interviews with shelter staff and residents, and individual interviews with a sample of 40 young women who had been homeless prior to using the shelter. The process evaluation showed that the shelter staff strived to utilize an empowerment philosophy in their relationships with residents, but that there were many challenges to implementing this philosophy. The outcome evaluation showed that, at a 3-month follow-up, the participants reported significant improvements in housing, income, independence, and life satisfaction, but most continued to experience poverty and a number of other difficulties. The results were discussed in terms of the implications for future research and the value and limitations of shelters for dealing with homeless youth. The need for more sustained and comprehensive program interventions and supportive social policies was underscored.
\end{abstract}

\section{INTRODUCTION}

The United Nations Children's Fund (1989) suggests that at least 100 million youth are homeless worldwide, and surveys on the prevalence of homeless youth have found that this number is increasing (Kurtz, Jarvis, \& Kurtz, 1991). In Canada, it has been estimated that every year upwards of 60,000 youth run away from family homes or child welfare placements, with many more young people being "kicked out" or "thrown away" from their family homes (Kariel, 1993).

Homeless young women appear to be a particularly vulnerable group. Research has shown that, compared with homeless young men, they tend to: (a) be younger and use shelters more frequently (Kufeldt, Durieux, \& Nimmo, 1992); (b) report higher ratings of mood disturbance, suicidal behaviour, and depression; (c) experience lower self-esteem (Maxwell, 1992; McCarthy \& Hagen, 1992); and (d) more likely have been sexually abused (Janus, McCormick, Burgess, \& Hartman, 1987). Also, compared with young women who are not homeless, homeless young women experience significantly elevated rates of physical and sexual abuse (Shinn, 1997) and, because of high-risk sexual activity and sexual abuse, are more likely to suffer from sex-

This paper is based on an M.A. Thesis in Community Psychology conducted by the first author under the supervision of the second author at Wilfrid Laurier University. The authors would like to extend their thanks to the staff and young women who use the services of the Emergency Shelter for Young Women in Ottawa, Ontario and to the three anonymous reviewers of the CJCMH who helped to improve this paper. Requests for reprints should be sent to Geoffrey Nelson. 
ually transmitted diseases, including AIDS (Kariel, 1993). The physical and sexual victimization of these women also is related to mental health problems and substance abuse (Wenzel, Koegel, \& Gelberg, 2000).

The growing number of youth who are running from abusive situations, intolerable home lives, or unsatisfactory placements in foster care or group homes has resulted in the development of shelters, which provide young people with a haven wherein they can be assured of housing, safety, food, warmth, clothing, and confidentiality (Gershowitz \& MacFarlan, 1990; Kufeldt et al., 1992; Teare, Peterson, Furst, Authier, Baker, \& Daly, 1994). Shelters often also provide counselling, support, and advocacy for the many life issues facing youth (e.g., housing, employment, education, health, family reunification, finances). However, a key feature of shelters is that they are time-limited, with most having a maximum stay of one month (Gershowitz \& MacFarlan, 1990).

Evaluative research is needed to determine how shelters for youth work and how successful they are in attaining their goals. Such research can focus on process evaluation (how program components are implemented), outcome evaluation (the extent to which service-users change and achieve the intended goals of the program), or both. With respect to process evaluation, Gershowitz and MacFarlan (1990) argue that a structured routine, the relationship between staff and youth, and referrals to other community agencies are key to the therapeutic potential of youth shelters. Further, Teare and colleagues (1994) found that staff provide a number of different services, including teaching social skills. In terms of outcome evaluation, there is evidence that shelters can be successful in helping clients to obtain housing (Glisson, Thyer, \& Fischer, 2001). However, we could not locate any outcome evaluations of youth shelters.

In any case, we believe that youth shelters can best be evaluated from the perspective of empowerment. Rappaport (1987) has defined empowerment as a process or mechanism by which "people, organizations or communities gain mastery over their affairs” (p. 122). Empowerment-based practice has a goal of helping individuals from disempowered groups to gain control over their lives (Gibson, 1993). Stark (1994) has suggested that staying too long in a shelter has detrimental effects and fosters individuals incapable of living "on the outside.” In response to this assertion, we were interested in knowing if a youth shelter is disempowering/dependencypromoting, or whether it facilitates empowerment by providing resources and support and by encouraging self-determination, choice, and independence.

The purpose of this research was to conduct a process and outcome evaluation of an emergency shelter for young women. The first objective focused on process evaluation and was concerned with the nature of the shelter experience, as perceived by residents, staff, and the researcher (Greene, 2000). In particular, we were interested in knowing whether staff used an empowering process in the implementation of different program components. The second objective focused on the outcomes achieved by participants three months after entering the emergency shelter. Specifically, we wanted to know if participants showed improvement in different areas of their lives after leaving the shelter. 


\section{METHOD}

\section{Setting}

The Emergency Shelter for Young Women in Ottawa has been in existence since 1995 and serves young women ages 12 to 20. The two main program components are: (a) the provision of emergency shelter, medical, and dental treatment, and (b) short-term counselling. The first component is designed to enhance the stability of the women's lives and to reduce stress by meeting, on a temporary basis, their basic needs of shelter, food, safety, and health care. The second component involves staff working with residents to develop goals and to follow through on the pursuit of those goals. While goals are individualized, typical outcome goals include increasing women's knowledge about resources (e.g., how to apply for social insurance and health cards) and increasing their connection to community resources (in areas pertaining to housing, education, employment, social assistance, longer-term counselling, etc.). The overarching goal of short-term counselling is to increase independence and enhance support.

Young women come to the shelter in a variety of ways. Many are fleeing from sexual/physical abuse at home, on the street, by a partner, or by acquaintances. Some are referred by schools or police, whereas others find the shelter on their own. Staff estimate that approximately half come from child welfare, foster homes, or other social services, and that approximately $20-30 \%$ are new immigrants to Canada who often have fled from war-torn countries and dangerous home lives. Many of those who use the shelter abuse drugs and alcohol and demonstrate self-injury. The average stay, according to agency staff, is 5.7 days per admission, and many use the shelter more than once.

The Young Women's Emergency Shelter is located in a building near downtown Ottawa, close to bus routes, shopping centres, schools, and many of Ottawa's community support agencies. Little about the building would indicate to outsiders that it is an emergency shelter. The two doors to the building remain locked at all times, and the identity of any visitor is verified before staff grant admission.

The shelter is made up of two floors. The staff office, a common room (furnished with oversized couches, books, a TV, and a VCR), and a small room with a computer and phone for resident use are on the top floor. Downstairs there are seven bedrooms for residents (five double rooms, two single rooms). Doors to bedrooms are kept locked at all times. At the end of the hall, there is a small room where the overnight staff member sleeps. Also downstairs is the shower and washroom, a small laundry room, and a staff office for counselling.

Two staff members are always on duty at the shelter. At 7 a.m., incoming staff are briefed by outgoing staff regarding events that occurred the night before, and are updated on the status of each young woman and her plans for the next day. By 9 a.m., under a rule known as the day plan, all residents must be out of the shelter and either attending school or looking for housing. Residents may come back to the shelter for lunch at noon. They are permitted back into the shelter at 4 p.m and may stay in for the evening if they choose. Dinner, which is catered by an outside agency, is served at 5 p.m. After dinner, each resident has a chore (e.g., clean-up) that must be completed before she is able to use the phone or watch the TV. After dinner and chores, residents are free to spend the evening as they please.

The shelter is staffed by seven full-time (including the shelter co-ordinator), two half-time, and nine part-time female workers. These women range in age from 
approximately 22 to 55, but the majority of women are under the age of 35 . All have a post-secondary education (BSW, MSW, or youth worker diplomas) and experience in front-line work with youth. Staff members work under a formalized set of values that includes: (a) being woman positive and respectful, (b) being accessible to women 24 hours a day and in both official languages (English and French), (c) being accountable for their interactions and support of young women, (d) providing a safe environment, (e) recognizing and striving to reduce power differentials between themselves and the young women, and (f) recognizing the rights of residents to make their own choices.

\section{Involvement of Stakeholders in the Research}

Staff members were enthusiastic to host the study and use the findings to improve shelter services. Two staff members (the shelter co-ordinator and one fulltime staff person) acted as advisors throughout the project. The researcher, a young woman in her 20s, held two focus groups with residents. The aim of the first focus group was to find out how to encourage women to participate in the study and to obtain suggestions for following up with them after they left the shelter. The second focus group addressed issues that residents were dealing with when they entered the shelter and initial impressions that they had about using the shelter. The researcher also was given the opportunity to speak with residents during monthly gatherings called "Taco and Talk" and with staff during weekly staff meetings. A third focus group was conducted with staff to learn about their experiences in working at the shelter.

\section{Participant Group, Sampling, and Follow-up}

As in other outcome studies completed with homeless populations (e.g., Toro, Rabideau, Bellavia, Daescheler, Wall, \& Thomas, 1997), a convenience sample was used. The first consenting 40 young women who entered the shelter were interviewed at intake. Half of this group had stayed at the shelter previously. The average age of participants was 17.5 years $(\mathrm{SD}=1.25)$. Approximately $38 \%(n=15)$ considered themselves visible minorities, with $12.5 \%$ describing themselves as black, $10 \%$ as aboriginal, $15 \%$ as mixed, and $10 \%$ as “other.” Most were born in Canada $(n=29)$, and $60 \%(n=24)$ had completed at least grade 10 . Half were living at a family or relative's home immediately before coming to the shelter $(n=20)$; others were "staying with a friend" $(n=8)$ or living in a private house or apartment $(n=5)$. Seven participants reported staying at group homes, shelters, boarding homes, or on the street prior to entering the shelter.

The agency offered an incentive of $\$ 20$ for participants to complete follow-up interviews three months later. During intake into the shelter, the participants were given cards with information about the study, including a "call back" date for three months later. Of the 40 participants for whom intake data were gathered, 30 followup interviews were completed (for an attrition rate of 25\%). The 10 women who could not be located were compared with the 30 who completed the follow-up interviews and no statistically significant differences were found on 15 variables (e.g., age, number of shelter stays, life satisfaction, individual and family risk factors, racial background, in-care involvement). Follow-up interviews lasted 20 to 60 minutes. 


\section{Individual Interviews}

A brief interview was administered by staff or college students doing placements when the young women first entered the shelter. Three months later, participants were contacted to complete follow-up interviews, which were conducted by the first author. Nineteen interviews were completed in person, and 11 were completed over the phone. Participants appeared to respond similarly to the in-person and telephone methods of collecting information. The questions focused on housing, education, employment, health, income, and counselling. Participants were asked to compare their status on these different outcome domains immediately prior to entering the shelter and at the time of the follow-up interview. They were also asked to rate the degree and direction of change for each of these outcome domains on a 7point scale (from significantly worse to significantly improved). This interview was based on another measure used with the same population in the same city (Totten \& Lundy, 1999). Cronbach's alpha (a measure of the internal consistency of the scale) for the 6-item outcome scale was .79. The participants were also asked open-ended questions about each of the outcome domains (e.g., Describe how your mental health has changed for better or worse since you entered the shelter).

An 11-item subjective life satisfaction scale was included in both the initial interview and the follow-up interview. This scale was taken from Lehman's Quality of Life interview (Lehman, 1988). Participants were asked to rate on a 7-point scale (from terrible to delighted) how they feel about their life as a whole, the safety of their living arrangements, and how they spend their spare time. The alphas for the life satisfaction measure were .79 at intake and .90 at follow-up.

\section{Participant Observation}

Participant observation is a method most often used by researchers completing ethnographies (Lofland, 1995) and has been used in other studies with homeless populations (Rosenthal, 1991; Thrasher \& Mowbray, 1995). The first author spent time "hanging out" at the shelter at breakfast, dinner time, and during the evenings. Drop-ins and other sites frequented by young women were also visited. Field notes were taken during participant observation sessions or immediately after leaving the setting. Informal conversations with the young women and staff were part of the participant observation process. Overall, 13 staff and over 30 young women were observed over approximately 18 staff meetings and 20 participant observation sessions at the shelter. Field notes were recorded for approximately 75 hours of participant observation.

\section{Analysis of Qualitative Data}

The responses to the open-ended questions in the individual three-month followup interviews were analyzed using standard qualitative data analysis procedures (Patton, 2002) to examine changes that the women had experienced since their involvement with the shelter. Answers to these questions (regarding housing, education, employment, etc.) were tape-recorded, transcribed, and coded for themes by the researcher as outlined. The themes captured the experiences or changes that were reported for each of the outcome areas. An audit trail was kept to enable the participants' responses to be verified.

Whereas the individual interviews were used to assess outcomes, the qualitative data gathered from the participant observation, the two resident focus groups, and the one staff focus group were used to understand resident and staff experiences of the 
implementation of the program components (e.g., the relationships between staff and residents). As Greene (2000) has suggested, a qualitative/constructivist approach is particularly well suited to exploring the question of how different stakeholders experience a program. An audit trail was used to keep track of all qualitative data. The researcher read through all of the field notes and the transcripts of the focus groups and began by categorizing responses. From these categories, the researcher constructed themes about stakeholders' experiences of the shelter (Patton, 2002). These themes were fed back to residents and staff, who verified their salience. Permission to use direct quotes was obtained from participants.

\section{RESULTS}

\section{Process Evaluation: The Shelter Experience}

Meeting Basic Needs of Food, Shelter, Safety, and Access to Health Care. When young women enter the emergency shelter, they are met by an encouraging and supportive staff who accept diversity and make efforts to recognize the strengths of all residents. For some, this is the first time that they have lived in such a supportive atmosphere.

When you come from an environment that's not supportive and they are all just supportive and when you get positive messages and you just feel really safe ... when I'm not here I miss them.

The women come to the shelter with a wide variety of needs. Most require the most basic needs of food, shelter, safety, and access to health care.

It's cold out there, I've been staying on the street . . . then I came to the shelter. Now I have somewhere to sleep and I can be warm.

Many residents have experienced threats of physical violence and are in hiding when they come into the shelter.

I was afraid it wasn't safe from outside people, I stayed awake the whole first night because I was afraid of someone getting in my room.

However, the confidential location, extensive alarm system, and staff routine put them at ease.

It feels safe because the doors are secure, and there are room checks, and there is an alarm ... the locks and alarms, that helps staff to know more, they take good safety precautions.

For many residents, the shelter quickly becomes such a place of safety and comfort that they do not want to leave. This often creates conflict with staff because the shelter is, by definition, a temporary place to stay. Staff members struggle with balancing the goals of meeting basic needs by providing a safe and supportive setting and promoting independence through short-term counselling.

Short-term Counselling. Short-term counselling involves setting goals and helping women to follow through on their goals. We found that the counselling process varied widely from resident to resident, and that resistance to and struggles with the counselling process were common.

All residents are required to participate in short-term counselling and set goals toward which they must work while staying at the shelter. The ability and willingness to set and work towards goals varies dramatically. For those who are unwilling to set or work towards goals, staff might deem them to be "ineligible" for the shelter. Some residents work with staff members to develop community plans and set goals regarding housing, education, health, and employment, while others only use the 
shelter as a place to sleep at night. There are also those who set some goals, but show little or half-hearted attempts at follow through on the goals.

A major staff role with regard to goal-setting is to provide residents with information about and help them make connections with other community resources and agencies. Staff work to develop extensive networks and connections with other agencies, services, and supports in the community. Residents are regularly guided to resources to help with housing, education, counselling, health, and mental health. Staff attempts to connect residents with as wide a number of supports as possible so that they know where to turn once they are on their own. The women are provided with contact names, pamphlets, phone numbers, and when necessary staff contact the community resource on a resident's behalf to link her with the service. On any given night in the shelter, outreach workers visit with residents over dinner or later in the common room. Ultimately, the goal of staff is to ensure that, once a resident leaves the shelter, she is not on her own and knows how to go about accessing help and support.

Staff members not only assist residents in setting goals, but they also coach them in how to attain these goals. Staff members attempt to ensure that residents are provided with tools, knowledge, and encouragement to achieve the goals they set. Just as staff members are held accountable for their actions, residents are also held accountable for their actions. This includes setting and following through on goals, respectful interactions with others, and working towards independence outside the shelter. As one staff person said, "If the young woman is not willing to help herself, then there is only so much we can do."

Just as goal-setting can be difficult with residents, the process of coaching residents to follow through on their goals often times is met with resistance. If residents do not appear to be making an effort to work toward their own goals and independence, staff explain why it is important that they must set and work towards goals. In speaking with several young women at the shelter, the first author learned that residents find it difficult to do things for themselves. For example, Natasha (not her real name), a new Canadian, was not comfortable with her command of English even though she spoke clearly and understood most conversations. Natasha had several health problems but was unhappy with the service from her current doctor and wanted to change doctors. One afternoon, the first author observed that Natasha asked every staff member present if she would call a new doctor and set an appointment for her. Several times, staff refused, but offered to sit with Natasha while she made the call and be available to help if she had questions. After some thought Natasha decided that she would call with a staff member sitting close by. The phone call went smoothly and assistance was not required. Afterwards she said that it made her feel good to have made the phone call on her own, and she thought she could phone without assistance next time.

Shelter guidelines are used by staff as a lever to push residents towards the goals that they set for themselves. Two guidelines, the day plan and curfew, are controversial. In the previous year, shelter staff implemented the day plan, in which residents are expected to be out of the shelter looking for housing or going to school. Residents have mixed reactions to the day plan and, for the most part, they do not like it while they live in the shelter. Many residents believe that it should be their choice to sleep in if they want and to attend school if they want. Others understand the logic behind the day plan, but believe that asking them to look for housing for six hours a 
day is unreasonable. As one young woman asked, "I mean . . . where are you supposed to go? I'm not in school!”

Some shelter residents understand the logic behind the day plan and approve of it. One young woman said that she needed someone to "kick her in the butt" and get out and find a place to live. Another said that "if they didn't make us get out we'd all have a free ride here.” There is some flexibility in the day plan. Staff members let residents know that they are willing to negotiate if there is a legitimate reason for not following a day plan, such as when a resident is sick or has arranged a meeting at the shelter regarding housing or services.

One other guideline, curfew, receives protest from young women. Residents reason that they are adults and should be able to decide what time they come home at night. Staff persons point out that many young women leave the shelter permanently without letting them know. If beds are held for residents who are out past curfew, there is no way of knowing if the resident is planning on returning.

There is a sense of ongoing struggle between staff and young women at the shelter over the guidelines. Staff believes that the guidelines are needed to ensure that residents do not become complacent. There are often other young women on a waiting list for a bed at the shelter, and there is a constant struggle by staff to determine if residents are devoted to moving forward with their lives and working toward independence. While the majority of those who enter the shelter want to improve their lives or are fleeing from chaotic home situations, there are those who use the shelter as a place to meet friends, and as close and convenient access to downtown and activities there. Negotiations over guidelines are common, with the underlying understanding that if a resident is not making progress toward goals or is consistently abusing guidelines, then she will soon be deemed ineligible to continue her stay at the shelter.

\section{Outcome Evaluation}

Quantitative Data. For the second research objective, paired sample $t$-tests were used to examine changes in participants' life circumstances. There was a significant improvement in housing. Proportionally more of the participants were living in private houses and apartments at the three-month follow-up $(x=.46, S D=.51)$ than immediately before entering the shelter $(x=.01, S D=.18), t(29)=4.71, p<.001$. Also, proportionally fewer were "staying with a friend" at the time of the follow-up $(x=.01, S D=.18)$ compared to immediately before entering the shelter $(x=.26, S D$ $=.45), t(29)=2.54, p<.05$.

Two significant effects were observed for income. A greater proportion were on social assistance at follow-up $(x=.57, S D=.50)$ compared to the initial interview $(x=$ $.27, \mathrm{SD}=.45), t(29)=3.07, p<.005$. Also, proportionally fewer participants had no income at follow-up $(x=.10, S D=.30)$ compared to the initial interview $(x=.23, S D$ $=63), t(29)=2.11, p<.05$. Finally, a significant effect was observed for life satisfaction. Life satisfaction scores significantly increased from the initial interview $(x=40.4 ., S D=11.14$. $)$ to the follow-up interview $(x=48.33 ., S D=15.30), t(29)=$ $3.79, p<.001$.

On the Totten and Lundy (1999) measure, the percentages of the sample rating the different outcome domains as improved were as follows: housing (66\%), education (43\%), employment (27\%), health (37\%), mental health (40\%), income (40\%), and counselling (37\%). Housing was the only outcome domain for which there was a clear cut indication of change on this measure. 
Qualitative Data. Qualitative data also were gathered from the participants during the follow-up interviews to give life to, to contextualize, and to enrich the understanding of the changes or lack of change that the women experienced in the following areas of their lives:

1. Housing. Most participants reported that housing had improved for them since they were now more stable where they lived. This stability in housing enabled them to start focusing on other areas of their lives.

I finally got out of the shelter and have my life straightened out . . . now that I don't have to look for a house I can look for a job, and I've already started working on this.

Those who reported that housing had remained unchanged or gotten worse often cited prejudice and discrimination (based on their age) by landlords as contributing to the lack of progress with housing.

Things are just unchanged, it's just the same old thing . . . people don't want to rent to freakin' kids. They're judging us, they think that we don't know how to pay bills and stuff and if they do rent to us it's some kind of a crack house.

For those participants who were living back at a family or relative's home at the time of the follow-up interview, their perceptions of this arrangement were quite variable. For some, it was a step backwards.

I'm back where I started, and that's not someplace that I want to be . . . it's like . . everything that I tried to do just didn't work out . . . it's depressing.

For others, after experiencing the sometimes harsh realities of being alone, in a shelter or on the street, being in their family home, although not the best, was their most desirable option at that point.

Before I didn't want to be here (at my mom's home), but since I've been in a group home and in a shelter, I like being here better. Even though I'm not on my own, I'm at home with people who love me.

2. Education. Many considered school to be very important, but few were attending school. Participants consistently conveyed that school became less of a priority when they were concerned about where they were going to sleep that night:

When you are living on the street, and you have no shower and no clean clothes, it (school) just doesn't work.

Many also thought that teachers and administrators at the schools were not sympathetic to their struggles outside of the classroom.

the thing is ... when you are out on your own they have no idea what it's like ... when I was at the shelter . . . it's hard . . . they [teachers] just don't have ideas about what it is like trying to concentrate on school when you are worrying about housing and welfare ...

In general, the participants all believed that school was important and, if they weren't currently enrolled, they planned on enrolling in the future.

3. Employment. Very few of the participants were currently employed. Those who were working generally were satisfied with their jobs, although they indicated that the wages were inadequate. Also, they reported that working was easier once they had found a permanent place to live outside of the shelter. Employment was not a priority for many participants. Finishing school was a higher priority than working, "I still need to go to school so I can’t work."

Others reported that they were often discriminated against in the work place, because of age, their appearance, or physical condition. 
I can't hold a job . . . when I go there they stare at my hands and arms and say that they don't want someone who cuts.

4. Physical health. Several participants reported experiencing health issues both when they came to the shelter and three months later. One problem was poor nutrition. Also, several women suggested that their health status had gotten worse since leaving the shelter.

Things are slightly worse . . . I think the shelter had more food and things I wanted to eat than here . . . people take turns making food, but it's not the same variety of food and I just don't eat as much . . . so I have low iron now and I just don't have much energy.

The money they [social assistance] give us isn't enough money to eat for the month even if we split it. We go to the food bank but they always give us food that has expired.

Others stated that their health had improved over the past three months. While at the shelter, some of these young women had been referred to a doctor or hospital where they received help which led to an improvement in their overall health.

5. Mental health. Almost all the participants reported experiencing some mental health issues both before entering the shelter and three months later. Many explained that they endure stress on a daily basis. This stress was attributed to poverty and unstable housing, which leads them to worry about where they are going to sleep that night, where they are going to obtain their next meal, and where they are going to get money for clothing in the harsh Ottawa climate. Young women also stated they experienced significant levels of depression, especially if they had to return to a family home where they do not get along with their parents or if they were unable to find permanent housing. These young women report feeling like a "failure."

I get stressed and depressed, about everything, but it's worse now because everything I did, it didn't work out, that makes me more stressed, that I'm back where I began.

Some suggested that, although their mental health improved while they were in the shelter, being on their own after leaving the shelter was stressful. Those who indicated improvements in their mental health at the follow-up attributed this improvement to the increased stability in their lives, the fact that they felt safe where they were staying, and the reality of no longer having to worry about where they were going to live.

6. Finances. Almost without exception, the women lived in poverty: many were on social assistance; a few had no current sources of income; and some lived on minimal contributions from family members. Those who were able to obtain employment still said that they did not make enough money. Those who cited improvements in income were able to get on social assistance. Those who are living on their own struggled to make ends meet each month.

I now have bills to pay, like phone bills and budgeting, I took the \$195 course [a course on how to budget on \$195 per month], but to try and implement it, it's really hard, I try to stock up but I always run out. I run out of toilet paper and milk every month. At the shelter you don't have to worry about that stuff.

7. Independence. While the participants reported improvement or lack of improvement in those areas of their lives described above, one overarching theme from the qualitative interview data was the experience of increased independence. Many of these women had lived in situations where their parents made all the decisions. When they entered the shelter, they were usually frightened and unaware of services and supports to help them. Many did not know how to cook or clean, and most had no 
idea of the housing, employment, and counselling services that could be used to support them. In speaking with several young women at the shelter, the first author learned that they often found it difficult to "do things for myself." However, after making phone calls, setting appointments, making arrangements on their own behalf, young women felt more capable of doing things on their own and living independently:

I've learned how to shop, I get the food that they got, I know how to clean now, we had one responsibility everyday to do, we have learned to set rules for our boyfriends.

I'm wiser now in how to get things done by myself, I didn't know how to do anything before, like how to get into school, or how to get social assistance. I was clueless about life. They taught me a lot of things.

At the shelter I learned how to live independently. They helped me budget, staff helped me to learn how to be on my own. Also, I'm not as shy as I used to be. My mom used to do things and make phone calls for me but now I do them on my own.

\section{DISCUSSION}

There are some notable limitations to this study which need to be overcome in further research in this area. First, the sample size was small, and women from only one shelter were sampled. In future research, larger and more representative samples should be studied. Second, the follow-up period of three months was quite short. While women experienced some gains over this short time period, the fact that many young women were socially isolated and did not have access to ongoing support calls into question how successful they would be in maintaining their gains in housing and life satisfaction over longer periods of time. Third, there was no comparison group for the outcome evaluation. The absence of a comparison group compromises the ability of this study to conclude that it was the shelter that was responsible for positive changes in outcomes. In spite of these limitations, this study helps to fill the gap in knowledge about the processes and outcomes of shelters for youth.

The first objective focused on a process evaluation of the implementation of the program components. We were particularly interested in understanding if staff used an empowering process in working with the young women. Empowerment-based practice has a goal of helping individuals from disempowered groups take control over their lives (Gibson, 1993). Qualitative data from participant observation, focus groups, and interviews demonstrated that staff did use an empowering process when working with residents. Basic needs of food, shelter, and safety were provided. Staff members were respectful of the women's desires, individuality, and right to chose the course of their lives. They made efforts to help residents become independent by linking them up with resources in the community, yet ensured that they were accountable for their actions. Staff members were encouraging, positive, and enthusiastic when dealing with residents and packed a great deal of support and counselling into a short time period with each resident.

While staff at the Young Women's Emergency Shelter strived to implement an empowerment philosophy, their relationships with residents were constrained by the short-term nature of stays at the shelter. Young women who enter the shelter are in crisis, and staff must deal with these crises constantly. Just as Gershowitz and MacFarlan (1990) observed in their examination of a youth shelter, guidelines and a structured routine are needed to ensure that residents are making the most of their 
limited time at the shelter. Residents often were frustrated by the "restrictions" placed on them (i.e., day plan, curfew), and staff were often overwhelmed by the demands of dealing with 12 to 14 young women in crisis and the short time they had to work with them. The restrictions placed on residents stem from the time and resource restrictions which the agency and the staff experience. Thus, the larger context has an impact on the degree to which staff members can implement an empowerment philosophy within the setting.

The second research objective was to examine three-month outcomes for participants. There were four outcomes that showed significant improvement over time: (a) obtaining housing, (b) obtaining social assistance, (c) increased independence, and (d) improved life satisfaction. Regarding housing, the quantitative data showed that significantly more participants lived in private houses/apartments and significantly fewer lived with friends after three months than before coming to the shelter. Also, two-thirds of the sample rated their housing as improved. In shelter circles, staying with a friend is called "couch surfing" and is generally considered the least stable form of housing next to staying on the streets. Also, the qualitative findings demonstrated that staff at the shelter not only helped young women to find housing, but also helped them to learn to live independently. Furthermore, participants suggested that, once they obtained permanent housing, they could focus on other areas of their life because they felt "stable." These findings are consistent with previous literature which has suggested that shelters can assist people in obtaining housing (e.g., Glisson et al., 2001).

With respect to income, significantly more participants were on social assistance and significantly fewer had no income after three months compared to when they entered the shelter. This finding can viewed in two ways. On one hand, there was improvement, and some income is better than none. On the other hand, the women remained in poverty. The qualitative data showed that worrying about money affected every aspect of their lives.

Many of the participants remarked that they had become more independent. This finding provides evidence contrary to Stark's (1994) assertion that shelters foster dependence. Participants indicated that they had learned how to shop, budget, search for housing, pay bills, and eat nutritiously. While many believed that they became more independent, they continue to express the need for support when they left the shelter. Ongoing supportive interventions are needed to help women cope with the many issues that they are facing.

Participants also reported significantly improved life satisfaction over the threemonth follow-up period. Since many of the participants entered the shelter in crisis, this finding likely indicates that their lives had become at least somewhat more stable.

There were no significant effects for several other outcomes, including employment, education, health, and mental health. It seems unlikely that a short-term intervention such as the shelter would be able to impact on these outcomes. More intensive support and housing interventions are likely needed to have a positive impact on these outcome areas (Toro et al., 1997; Tsemberis \& Eisenberg, 2000).

\section{CONCLUSION}

Although the Young Women's Emergency Shelter is an effective support for many young women, like all shelters, it is a reactive and micro-level intervention that 
does not address larger social justice issues that lead to homelessness (Toro \& Warren, 1999). Homelessness and poverty go hand in hand. While Canada is a prosperous nation, it has the second highest child poverty rate of all industrialized countries (Prilleltensky \& Nelson, 2000). Moreover, the federal government has shifted responsibility for low-income housing to the provinces, with no corresponding shifts in the allocation of fiscal resources. Similarly, the government of Ontario has shifted responsibility for housing to the municipalities with no corresponding shifts in resources. The net result is that cities such as Ottawa have not been able to create sufficient housing for homeless and low-income populations. Moreover, the government of Ontario has cut social assistance payments to people like the women in this study by more than $20 \%$.

To promote wellness and eradicate homelessness, there needs to be a shift in social policies and changes in values at the societal level (Prilleltensky \& Nelson, 2000; Toro \& Warren, 1999). The growing polarization of income distribution needs to be addressed in order to abolish the need for homeless shelters. The lack of affordable housing is a barrier to ending homelessness that needs to be addressed at the policy level (Toro \& Warren, 1999). Ending homelessness will involve offering more collective and preventative approaches and policy initiatives (Prilleltensky \& Nelson, 2003). We need to adopt values that encourage healthy and safe living for all Canadians, not just options for safe shelters once individuals find themselves without a home. From the results of this study, the need for ongoing support interventions that address housing, education, mental health, and substance abuse problems is quite apparent.

\title{
RÉSUMÉ
}

\begin{abstract}
Dans le but d'évaluer les méthodes et les résultats d'un refuge court terme, des données quantitatives et qualitatives ont été recueillies par le biais de l'observation participante, d'entrevues avec le personnel et les résidentes du refuge en forme de groupes de discussion, ainsi que d'entrevues avec un échantillon de 40 jeunes femmes qui étaient itinérantes avant leur entrée au refuge. L'évaluation des méthodes a démontré que le personnel du refuge cherchait à appliquer une philosophie de prise en charge à ses relations avec les résidentes, mais que l'implantation de cette approche se heurtait à plusieurs défis. L'évaluation des résultats a révélé qu'à l'étape du suivi de 3 mois, les participantes avaient noté des améliorations significatives aux plans du logement, du revenu, de l'indépendance et de la satisfaction générale, mais que la plupart continuaient d'être confrontées à des conditions de pauvreté et d'autres difficultés. Les résultats ont été analysés en termes de leur implication pour des recherches à venir et en termes de la valeur et des limitations des refuges comme solution pour les jeunes sans abri. L'analyse a également mis en lumière la nécessité d'établir des programmes d'intervention plus soutenus et plus complets, ainsi que des politiques sociales apportant un soutien accru.
\end{abstract}

\section{REFERENCES}

Gershowitz, M., \& MacFarlan, A. (1990). The therapeutic potential of emergency shelters. In J.P. Anglin, C.J. Denhom, R.V. Ferguson, \& A.R. Pence (Eds.), Perspectives in professional child and youth care (pp. 95-103). Binghampton, NY: Haworth Press.

Gibson, C.M. (1993). Empowerment theory and practice with adolescents of color in the child welfare system. Families in Society, 74(7), 387-396.

Glisson, G.M., Thyer, B.A., \& Fischer, R.L. (2001). Serving the homeless: Evaluating the 


\section{CANADIAN JOURNAL OF COMMUNITY MENTAL HEALTH}

effectiveness of homeless shelter services. Journal of Sociology and Social Welfare, 28(4), 89-97.

Greene, J.C. (2000). Understanding social programs through evaluation. In N.K. Denzin \& Y.S. Lincoln (Eds.), Handbook of qualitative research ( $2^{\text {nd }}$ Ed., pp. 981-999). Thousand Oaks, CA: Sage.

Janus, M.D., McCormack, A., Burgess, A., \& Hartman, C. (1987). Adolescent runaways: Causes and consequences. Toronto: Lexington Books.

Kariel, P. (1993). New directions: Stepping out of street life. Calgary: Greenways Press.

Kufeldt, K., Durieux, M., \& Nimmo, M. (1992). Providing shelter for street youth: Are we reaching those in need? Child Abuse and Neglect, 16(2), 187-199.

Kurtz, D. Jarvis, S., \& Kurtz, G. (1991). Problems of homeless youths: Empirical findings and human services issues. Social Work, 36(4), 309-314.

Lehman, A. (1988). A quality of life interview for the chronically mentally ill. Evaluation and Program Planning, 11(1), 51-62.

Lofland, J. (1995). Analytic ethnography: Features, failings, and futures. Journal of Contemporary Ethnography, 24(1), 30-67.

Maxwell, B.E. (1992). Hostility, depression, and self-esteem among troubled and homeless adolescents in crisis. Journal of Youth and Adolescence, 21(2), 139-150.

McCarthy, B., \& Hagen, J. (1992). Surviving on the street: The experiences of homeless youth. Journal of Adolescent Research, 7(4), 412-430.

Patton, M.Q. (2002). Qualitative evaluation and research methods ( ${ }^{\text {nd }}$ Ed.). Thousand Oaks, CA: Sage

Prilleltensky, I., \& Nelson, G. (2000). Promoting child and family wellness: Priorities for psychological and social Interventions. Journal of Community and Applied Social Psychology, 10(2), 85-105.

Rappaport, J. (1987). Terms of empowerment/exemplars of prevention: Toward a theory for community psychology. American Journal of Community Psychology, 15(2), 121-144.

Rosenthal, R. (1991). Straighter from the source: Alternative methods of researching homelessness. Urban Anthropology, 20(2), 109-125.

Shinn, M. (1997). Family homelessness: State or trait. American Journal of Community Psychology, 25(6), 755-769.

Stark, L.R. (1994). The shelter as "total institution": An organizational barrier to remedying homelessness. American Behavioral Scientist, 37(4), 553-562.

Teare, J.F., Peterson, R.W., Furst, D., Authier, K., Baker, G., \& Daly, D.L. (1994). Treatment implementation in a short-term emergency shelter program. Child Welfare, 73(4), 271-281.

Thrasher, S., \& Mowbray, C. (1995). A strengths perspective: An ethnographic study of homeless women with children. Health and Social Work, 20(2), 93-101.

Toro, P.A., Rabideau, J.M.P., Bellavia, C.W., Daeschler, C.V., Wall, D.D., \& Thomas, D.M. (1997). Evaluating an intervention for homeless persons: Results of a field experiment. Journal of Consulting and Clinical Psychology, 65(3), 476-484.

Toro, P.A., \& Warren, M.G. (1999). Homelessness in the United States: Policy considerations. Journal of Community Psychology, 27(2), 119-136.

Totten M., \& Lundy, C. (1999). Monitoring agency effectiveness: The use of outcome measures. Canadian Social Work Review, 16(1), 87-102.

Tsemberis, S., \& Eisenberg, R.F. (2000). Pathways to housing: Supported housing for streetdwelling homeless individuals with psychiatric disabilities. Psychiatric Services, 51(4), 487493.

United Nations Children's Fund (1989). Annual Report. New York: Author.

Wenzel, S.L., Koegel, P., \& Gelberg, L. (2000). Antecedents of physical and sexual victimization among homeless women: A comparison to homeless men. American Journal of Community Psychology, 28(3), 367-390. 